\title{
Partisipasi Ibu Balita Ke Posyandu Melati di Desa Sungai Bertam, Kabupaten Muaro Jambi Tahun 2020
}

\section{Participation of Mothers with Children Under Five Years to Posyandu Melati in Sungai Bertam Village, Muaro Jambi Regency in 2020}

\author{
Winda Triana ${ }^{1 *}$, Pahrur Razi ${ }^{1,}$ Solihin Sayuti ${ }^{1}$ \\ ${ }^{1}$ Jurusan Promosi Kesehatan, Politeknik Kesehatan Kementerian Kesehatan Jambi, Kota Jambi 36128
}

*Korespondensi penulis:

windatriana60@gmail.com

\section{ABSTRAK}

Latar Belakang. Pelayanan kesehatan bulanan balita di Posyandu diantaranya adalah pelaksanaan pemeriksaan kesehatan balita, penimbangan berat badan, pemantauan gizi, pemberian vitamin A, dan konsultasi kesehatan serta imunisasi. Di Puskesmas PIR II Bajubang wilayah Desa Sungai Bertam, terdapat Posyandu Melati dengan cakupan kunjungan balitanya yang sangat rendah. Setiap bulan hanya 50\% dari jumlah sasaran 70 balita (D/S) yang datang berkunjungan.

Tujuan. Penelitian ini bertujuan untuk mengetahui partisipasi Ibu balita ke Posyandu Melati di Desa Sungai Bertam.

Metode. Jenis penelitian menggunakan deskriptif analitik, populasi pada penelitian ini adalah seluruh Ibu balita yang ada di Posyandu Melati Desa Sungai Bertam berjumlah 70 orang, dengan teknik menggunakan teknik total sampling.

Hasil. 68,6\% responden berpartisipasi baik ke Posyandu, 75,7\% responden memiliki pengetahuan yang baik, $57,1 \%$ responden mempunyai sikap yang baik dan 51,4\% mempunyai motivasi yang baik. Terdapat hubungan yang bermakna antara partisipasi Ibu balita dalam penimbangan ke Posyandu terhadap pengetahuan ( $p$-value $0,004)$, sikap ( $p$-value 0,000) dan motivasi ( $p$-value 0,000). Sedangkan untuk peran Kader tidak menunjukkan hubungan yang bermakna terhadap partisipasi Ibu balita ke Posyandu karena mempunyai $p$-value 0,843 .

Kesimpulan. Ada hubungan yang bermakna antara pengetahuan, sikap dan motivasi dengan partisipasi Ibu dalam melakukan penimbangan di Posyandu Melati Desa Sungai Bertam Kabupaten Muaro Jambi Tahun 2020 .

Kata Kunci: partisipasi, balita, Posyandu

\begin{abstract}
Introduction. Monthly health services for children under five years at Posyandu include implementing health checks, weighing, monitoring nutrition, giving vitamin A, health consultations and immunizations. At the PIR II Bajubang Puskesmas in the Sungai Bertam Village area, there is a Melati Posyandu with a very low coverage of toddler visits. Every month only $50 \%$ of the target number of 70 toddlers $(D / S)$ come to visit.

Objective. This study aimed to determine the participation of mothers with children under five years in the Posyandu Melati in Sungai Bertam Village.

Methods. This research used a descriptive analytic, the population in this study were all mothers with children under five years at the Posyandu Melati, amounting to 70 people, with a technique using the total sampling

Results. $68.6 \%$ of respondents participated well in Posyandu, $75.7 \%$ of respondents had good knowledge, $57.1 \%$ had good attitudes and $51.4 \%$ had good motivation. There is a significant relationship between the participation of mothers with children under five in weighing to Posyandu on knowledge (p-value 0.004), attitude ( $p$-value 0.000) and motivation (p-value 0.000). Meanwhile, the role of Cadre does not show a significant relationship to the participation of mothers under five to the Posyandu because it has a p-value of 0.843

Conclusion. There is a significant relationship between knowledge, attitude and motivation with mother's participation in weighing at the Melati Posyandu Sungai Bertam Village, Muaro Jambi Regency in 2020.
\end{abstract}

Keywords: participation, toddlers, Posyandu 


\section{LATAR BELAKANG}

Deteksi dini kasus gizi kurang dan gizi buruk dapat dilakukan melalui penimbangan balita. Jika secara rutin menimbang balita, maka pertumbuhan balita dapat dipantau secara intensif. Hal ini dimaksudkan apabila berat badan anak tidak naik atau jika ditemukan penyakit, dapat segera dilakukan upaya pemulihan dan pencegahan, agar tidak menjadi gizi kurang atau gizi buruk. Semakin cepat ditemukan kasusnya akan mengurangi resiko kematian sehingga angka kematian akibat gizi buruk dapat ditekan. ${ }^{1}$

Pemantauan pertumbuhan balita sangat penting dilakukan untuk mengetahui adanya hambatan pertumbuhan (growth faltering) secara dini. Untuk mengetahui pertumbuhan tersebut maka penimbangan setiap bulan sangat diperlukan. Penimbangan balita sangat penting untuk deteksi dini kasus gizi kurang dan gizi buruk. ${ }^{2}$ Cakupan penimbangan balita di Posyandu (D/S) merupakan indikator yang berkaitan dengan cakupan pelayanan gizi pada balita, cakupan pelayanan kesehatan dasar khususnya imunisasi serta prevelensi gizi kurang. Semakin tinggi cakupan D/S, semakin tinggi cakupan vitamin A. Semakin tinggi cakupan imunisasi dan semakin rendah prevalensi gizi kurang sehingga partisipasi masyarakat dalam Posyandu sangat diperlukan guna mendapatkan pelayanan kesehatan dan gizi pada balita. ${ }^{2}$

Kasus gagal tumbuh pada anak balita di Indonesia masih tinggi, Organisasi Kesehatan Dunia (WHO) menempatkan Indonesia sebagai negara ketiga dengan kasus tertinggi di Asia. ${ }^{3}$ Berdasarkan data Riset Kesehatan Dasar tahun $2018^{4}$, angka stunting di Indonesia mencapai $30,8 \%$. Sementara target WHO angka stunting tidak boleh melebihi dari $20 \% .^{3}$ Tahun 2018 persentase balita usia 6 - 59 bulan ditimbang di Indonesia $68,37 \%$ per bulannya, namun ini terjadi penurunan dari tahun sebelumnya yang mana pada tahun 2017 cakupan penimbangan balita sebesar $77,95 \% .^{5}$

Partisipasi kunjungan Ibu balita ke Posyandu untuk melakukan penimbangan balita dikatakan baik jika minimal empat kali ditimbang di Posyandu secara berturut-turut dalam enam bulan. Dikatakan tidak baik apabila kurang dari empat kali secara berturut-turut ke Posyandu dalam enam bulan. ${ }^{2}$ Pelayanan kesehatan bayi dan balita yang dilakukan di Posyandu setiap bulan di Indonesia meliputi pemeriksaan kesehatan balita, penimbangan berat badan, pemantauan status gizi, pemberian vitamin $\mathrm{A}$, pemberian imunisasi konsultasi masalah kesehatan dan pelayanan kesehatan lainnya.

Pencapaian penimbangan balita (D/S) Provinsi Jambi untuk Tahun 2018 sebesar $76,05 \%$. Angka ini menunjukan peningkatan pencapaian dari tahun sebelumnya yaitu $72,49 \% .^{6}$ Penimbangan balita (D/S) berdasarkan kabupaten/kota Tahun 2018 di Provinsi Jambi yaitu, Kabupaten Muaro Jambi menempati urutan kelima dari 11 kabupaten/kota yang ada di Propinsi Jambi sebesar 75,5\%. ${ }^{6}$

Partisipasi berarti peran serta seseorang atau kelompok masyarakat dalam proses pembangunan baik dalam bentuk pernyataan maupun dalam bentuk kegiatan dengan memberi masukan pikiran, tenaga, waktu, keahlian, modal atau materi, serta ikut serta memanfaatkan dan menikmati hasil-hasil pembangunan. ${ }^{7}$ Berdasarkan penelitian Umasangaji ${ }^{8}$, keberhasilan pelaksanaan Posyandu di Desa Waitina Kecamatan Mangoli Timur karena partisipasi aktif dari masyarakat dan juga karena keterlibatan Lembaga Pemberdayaan masyarakat secara aktif dan terus menerus. Ini terbukti dengan menurunnya tingkat kematian ibu dan bayi serta dewasa karena masyarakat telah menerapkan pola hidup sehat.

Menurut penelitian Nurdin et al. ${ }^{9}$, terdapat hubungan antara pengetahuan ibu ( $p$-value $=$ $0,021, \mathrm{OR}=3,098)$, motivasi $(p$-value $=0,003$, $\mathrm{OR}=4,332)$, peran kader ( $p$-value $=0,027, \mathrm{OR}=$ $2,971)$ terhadap partisipasi kunjungan ibu balita ke Posyandu.

Kabupaten Muaro Jambi mempunyai 21 Puskesmas salah satunya terdapat Puskesmas PIR II Bajubang. Pencapaian penimbangan D/S pada balita tahun 2018 sebesar 51,8\% rangking 15 dari 21 Puskesmas yang ada. ${ }^{10}$ Desa Sungai Bertam sendiri merupakan cakupan wilayah kerja dari Puskesmas PIR II Bajubang. Desa Sungai Bertam memiliki 5 Posyandu yang diantaranya terdapat Posyandu Melati dengan cakupan kunjungan balitanya sangat rendah dari jumlah sasaran yang ada (D/S), dari sasaran 70 balita yang berkunjungan setiap bulannya hanya $50 \% .^{11}$

Hasil survey awal yang telah dilakukan kepada ibu yang memiliki anak balita di wilayah Posyandu Melati yaitu ibu rajin membawa anak balitanya ke Posyandu pada tahun pertama untuk 
mendapatkan imunisasi dasar lengkap dan alasan Ibu tidak lagi datang ke Posyandu dikarenakan tidak ada lagi imunisasi yang akan diberikan kepada balitanya.

\section{METODE}

Penelitian deskriptif-analitik ini menggunakan rancangan cross sectional. Teknik pengambilan sampel menggunakan total sampling. Data primer didapat dengan pengisian kuesioner pada ibu balita, penelitian dilakukan bulan Januari Juni 2020. Populasi seluruh ibu balita yang ada di Posyandu Melati Desa Sungai Bertam berjumlah 70 orang. Analisa data secara univariat dan bivariat.

\section{HASIL}

Berdasarkan hasil penelitian didapat gambaran partisipasi ibu balita dalam penimbangan ke Posyandu meliputi pengetahuan, sikap, motivasi dan peran kader. Dari tabel 1 didapatkan informasi bahwa $68,6 \%$ responden berpartisipasi baik ke Posyandu. Pengetahuan yang baik dimiliki oleh $75,7 \%$ responden. Terdapat $57,1 \%$ responden yang mempunyai sikap yang baik dan $51,4 \%$ mempunyai motivasi yang baik. Responden yang mengatakan peran kader yang baik adalah $97,1 \%$.

Pada tabel 2 menunjukkan hubungan pengetahuan, sikap, motivasi dan peran kader dengan partisipasi Ibu balita dalam penimbangan ke Posyandu. Terdapat hubungan yang bermakna antara pengetahuan ( $p$-value 0,004$)$, sikap ( $p$-value $0,001)$ dan motivasi ( $p$-value 0,001) dengan partisipasi Ibu balita dalam penimbangan ke Posyandu. Tidak ada hubungan antara peran kader tidak menunjukkan hubungan yang bermakna terhadap partisipasi Ibu balita ke Posyandu karena mempunyai $p$-value $>0,05$ yaitu 0,843 .

Tabel 1. Distribusi Responden Berdasarkan Partisipasi, Pengetahuan, Sikap, Motivasi Ibu Balita dan Peran Kader dalam Penimbangan ke Posyandu Melati di Desa Sungai Bertam Kabupaten Muaro Jambi Tahun $2020(n=70)$

\begin{tabular}{|c|c|c|}
\hline Variabel & $\mathbf{F}$ & $\%$ \\
\hline \multicolumn{3}{|l|}{ Partisipasi } \\
\hline - Baik & 48 & 68,6 \\
\hline - $\quad$ Kurang baik & 22 & 31,4 \\
\hline \multicolumn{3}{|l|}{ Pengetahuan } \\
\hline - Baik & 53 & 75,7 \\
\hline - Kurang baik & 17 & 24,3 \\
\hline \multicolumn{3}{|l|}{ Sikap } \\
\hline Positif & 40 & 57,1 \\
\hline - Negatif & 30 & 42,9 \\
\hline \multicolumn{3}{|l|}{ Motivasi } \\
\hline - Baik & 36 & 51,4 \\
\hline - Kurang baik & 34 & 48,6 \\
\hline \multicolumn{3}{|l|}{ Peran Kader } \\
\hline - Baik & 68 & 97,1 \\
\hline - $\quad$ Kurang baik & 2 & 2,9 \\
\hline
\end{tabular}

Tabel 2. Distribusi Hubungan Pengetahuan Sikap, Motivasi dan Peran Kader dengan Partisipasi Ibu Balita dalam Penimbangan Ke Posyandu Melati di Desa Sungai Bertam Kabupaten Muaro Jambi Tahun 2020

\begin{tabular}{|c|c|c|c|c|c|c|c|c|}
\hline \multirow{3}{*}{ Variabel } & \multirow{3}{*}{ Kategori } & \multicolumn{4}{|c|}{ Partisipasi } & \multirow{2}{*}{\multicolumn{2}{|c|}{ Total }} & \multirow{3}{*}{$p$-value } \\
\hline & & \multicolumn{2}{|c|}{ Kurang Baik } & \multicolumn{2}{|c|}{ Baik } & & & \\
\hline & & $\mathbf{n}$ & $\%$ & $\mathbf{N}$ & $\%$ & $\mathbf{n}$ & $\%$ & \\
\hline \multirow[t]{2}{*}{ Pengetahuan } & Kurang Baik & 0 & 0 & 17 & 100 & 17 & 100 & \multirow{2}{*}{0,004} \\
\hline & Baik & 22 & 41,5 & 31 & 58,5 & 53 & 100 & \\
\hline \multirow[t]{2}{*}{ Sikap } & Negatif & 22 & 73,3 & 8 & 26,7 & 30 & 100 & \multirow{2}{*}{0,001} \\
\hline & Positif & 0 & 0 & 40 & 100 & 40 & 100 & \\
\hline \multirow[t]{2}{*}{ Motivasi } & Kurang Baik & 0 & 0 & 34 & 100 & 34 & 100 & \multirow{2}{*}{0,001} \\
\hline & Baik & 22 & 61,1 & 14 & 38,9 & 36 & 100 & \\
\hline \multirow[t]{2}{*}{ Peran Kader } & Kurang Baik & 0 & 0 & 2 & 100 & 2 & 100 & \multirow{2}{*}{0,843} \\
\hline & Kader Baik & 22 & 32,4 & 46 & 67,6 & 68 & 100 & \\
\hline
\end{tabular}




\section{PEMBAHASAN}

Berdasarkan hasil penelitian sebagian besar responden di Posyandu Melati Desa Sungai Bertam sudah berpartisipasi dengan baik dalam melakukan penimbangan ke Posyandu. Program Posyandu akan bermanfaat jika balita berkunjung ke Posyandu secara teratur. Keteraturan balita berkunjung ke Posyandu sangat tergantung dari partisipasi ibu untuk membawa balitanya berkunjung ke Posyandu. Partisipasi ibu atau kunjungan ibu balita ke Posyandu dipengaruhi oleh faktor waktu luang ibu dan pendapatan keluarga. Untuk meningkatkan kepatuhan kunjungan Ibu balita ke Posyandu diharapkan ibu balita dapat menyediakan waktu untuk berpartisipasi aktif datang ke Posyandu. Di Posyandu ibu akan memperoleh bimbingan dari kader sehingga ibu balita mendapatkan informasi tentang kesehatan balitanya. ${ }^{12}$

Pengetahuan ibu balita di Desa Sungai Bertam dipengaruhi oleh beberapa hal yaitu diantaranya usia ibu balita, pekerjaan, tingkat pendidikan, pengetahuan merupakan domain yang sangat penting bagi terbentuknya tindakan seseorang (overt behavior). ${ }^{13}$ Pendidikan orang tua merupakan salah satu faktor yang penting dalam Posyandu, karena dengan adanya pendidikan yang baik, orang tua dapat menerima segala informasi dari luar terutama tentang kesehatan anak atau dalam keaktifan membawa balitanya ke Posyandu. ${ }^{14}$ Perilaku yang dilakukan berdasarkan pada pengetahuan akan bertahan lebih lama dan kemungkinan menjadi perilaku yang melekat pada seseorang dibandingkan jika tidak berdasarkan pengetahuan. ${ }^{13}$ Masih adanya sebagian kecil responden yang tidak memiliki pengetahuan baik, maka disarankan agar ibu balita selain rutin mengikuti kegiatan Posyandu balita, Ibu juga harus lebih berperan aktif dalam kegiatan Posyandu balita, seperti bertanya pada meja penyuluhan atau bertanya langsung kepada Kader Posyandu balita.

Kader Posyandu yang berperan disini adalah kader Posyandu melaksanakan tugasnya sebelum, saat, maupun sesudah kegiatan Posyandu dilaksanakan. Kader Posyandu yang tidak berperan adalah kader Posyandu yang tidak rutin datang dalam kegiatan Posyandu setiap bulan. Hal tersebut terjadi karena menjadi seorang kader bukan merupakan pekerjaan utama.

Penelitian ini menunjukkan adanya hubungan antara pengetahuan dengan partisipasi ibu balita dalam penimbangan ke Posyandu. Salah satu faktor yang mempengaruhi perilaku seseorang adalah pengetahuan. Dengan pengetahuan maka akan menghasilkan perubahan perilaku. Semakin baik tingkat pengetahuan maka wawasan atau informasi tentang Posyandu juga baik dan ibu juga lebih aktif dalam kegiatan Posyandu. ${ }^{15}$ Berdasarkan penelitian hubungan pengetahuan dengan partisipasi ibu balita dalam kegiatan Posyandu balita di Desa Sungai Bertam, Kabupaten Muaro Jambi. Masih terdapat ibu yang berpengetahuan baik, sikap positif dan motivasi baik tetapi tidak rutin mengikuti kegiatan Posyandu hal tersebut dikarenakan pada saat dilaksanakan kegiatan Posyandu ibu memiliki kesibukan seperti sedang bertepatan dengan panen. Beberapa ibu balita merasa bahwa yang balitanya sudah berusia lebih dari tiga tahun sudah tidak wajib untuk datang ke Posyandu.

Ibu balita merasa membawa balitanya ke Posyandu bisa dilakukan di kegiatan Posyandu bulan selanjutnya. Ibu yang berpengetahuan kurang baik dan bersikap negative tetapi rutin mengikuti kegiatan Posyandu. Hal ini dikarenakan ibu merasa dengan mengikuti arahan dari kader Posyandu untuk mengikuti Posyandu balita setiap bulan, akan membuat pertumbuhan balitanya terpantau.

Kader yang tidak berperan tetapi Ibu balita tetap berpartisipasi dalam kegiatan Posyandu balita. Hal tersebut dikarenakan Ibu merasa harus membawa balitanya ke Posyandu karena selain dapat mengetahui pertumbuhan dan perkembangan balita melalui kegiatan di Posyandu. Selain itu, ibu juga dapat bertemu dan berkumpul dengan ibu balita yang lain untuk saling bertukar informasi tentang balitanya.

Hasil penelitian sejalan dengan penelitian Amalia $^{16}$ yang menyatakan bahwa dengan adanya bimbingan secara aktif dari kader maka ibu balita akan cenderung berperilaku ke arah yang positif yaitu patuh berkunjung ke Posyandu pada tiap bulannya. Lebih lanjut, hasil penelitian ini sama dengan hasil penelitian yang dilakukan oleh Nelly dalam Amalia ${ }^{16}$ yang menunjukkan bahwa terdapat hubungan 
yang bermakna peran kader dalam kunjungan Posyandu balita.

\section{KESIMPULAN}

Sebagian besar responden memiliki partisipasi baik, pengetahuan baik, sikap baik dan motivasi baik serta peran kader baik. Ada hubungan yang bermakna antara pengetahuan, sikap, motivasi dan peran kader dengan partisipasi ibu dalam melakukan penimbangan di posyandu Melati Desa Sungai Bertam Kabupaten Muaro Jambi Tahun 2020.

\section{SARAN}

Kerjasama lintas sektoral melibatkan masyarakat, pemerintah dan swasta adalah upaya pengembangan kemandirian masyarakat yang sebaiknya dilakukan secara berkelanjutan. Dukungan tokoh masyarakat, organisasi pengajian, PKK perlu diupayakan untuk memberi motivasi dalam mengerakkan kegiatan Posyandu. Perlunya diberikan permainan, penyuluhan, arisan untuk menambah inovasi dan menyediakan sarana dan tenaga kesehatan yang diperlukan untuk penyelenggaraan Posyandu ini agar lebih atraktif

\section{UCAPAN TERIMA KASIH}

Penulis mengucapkan terima kasih kepada Kepala Puskesmas Pir II Bajubang, Kepala Desa Sungai Bertam, seluruh ibu balita dan kader Posyandu Melati di Desa Sungai Bertam Kabupaten Muaro Jambi yang telah terlibat dan berpartisipasi dalam penelitian.

\section{DAFTAR REFERENSI}

1. Kemenkes RI, 2019. Profil Kesehatan Indonesia. Jakarta.

2. Kemenkes RI, 2017. Profil Kesehatan Indonesia. Jakarta.

3. World Health Organization (WHO), Achieving universal health coverage for the world's 1.2 billion adolescents, 2018.

4. Kemenkes RI, (2018), Hasil Utama RISKESDAS 2018, Kemenkes RI: Badan Penelitian dan Pengembangan Kesehatan.
5. Kemenkes RI, (2017), Hasil data informasi kesehatan 2016, Kemenkes RI: Badan Penelitian dan Pengembangan Kesehatan.

6. Dinas Kesehatan Provinsi Jambi, 2018.Profil Dinas Kesehatan Propinsi Jambi

7. Sumaryadi Nyoman I. 2010.Sosiologi Pemerintahan Bogor. Ghalia Indonesia

8. Umasangaji Isnain.M. 2016. Partisipasi Masyarakat Pada Program Posyandu di Desa Waitina Kecamatan Mangoli Timur. Journal 2016

9. Nurdin dkk, 2018. Faktor-Faktor Yang Berhubungan dengan Partisipasi Ibu Balita kePosyandu di Jorong Tarantang. Jurnal Endurance: Kajian Ilmiah Problema Kesehatan Vol 4 (1) Februari 2019: 220-234.

10. Dinas Kesehatan Kabupaten Muaro Jambi, 2018. Laporan Program Gizi Kabupaten Muaro Jambi

11. Laporan Gizi Puskesmas Pir 2 Bajubang 2019

12. Yuniarti Sri, 2015. Asuhan Tumbuh Kembang Neonatus Bayi Balita Anak Prasekolah. PT Refika Aditama

13. Soekidjo Notoatmodjo, 2012. Promosi kesehatan dan ilmu perilaku. Rineka Cipta. Jakarta.

14. Nila Eriza Sativa. Faktor-faktor yang berhubungan dengan keaktifan Ibu balita dalam kegiatan Posyandu Dusun Mlangi Kabupaten Sleman [naskah publikasi]. Yogyakarta: Universitas 'Aisyiyah; 2006

15. Notoatmodjo, 2010 .Ilmu Perilaku Kesehatan. Rineka Cipta. Jakarta

16. Endra Amalia, Syahrida, Yessi Andriani, 2018 faktor mempengaruhi kunjungan ibu membawa balita ke posyandu kelurahan tanjung pauh tahun 2018 Jurnal Kesehatan Perintis (Perintis's Health Journal) Volume 6 Nomor 1 Tahun 2019 P-ISSN : 2355-9853 EISSN : 2622-4135 